\title{
Sob o domínio do duplo: um estudo comparativo de dois contos de Ignácio de Loyola Brandão
}

\author{
Antonia Marly Moura da Silva ${ }^{1}$ \\ Francisco Edson Gonçalves Leite ${ }^{2}$
}

\section{Apropriações metafóricas do duplo na literatura}

Nas sociedades modernas, a problemática da identidade adquire capital importância, refletindo as profundas transformações em curso na estrutura social. Nesse contexto instável, as identidades centradas e unificadas, que promoviam estabilidade para o sujeito, não encontram mais espaço: "as velhas identidades, que por tanto tempo estabilizaram o mundo social, estão em declínio, fazendo surgir novas identidades e fragmentando o indivíduo moderno, até aqui visto como um sujeito unificado" (Hall, 2006, p. 10).

Por estarem intrinsecamente relacionadas à problemática da identidade, as representações do duplo na literatura apropriam-se metaforicamente dessa questão, pois se inserem nesse debate maior sobre a construção das identidades ao longo da história. No entanto, vale destacar que a temática do duplo não é exclusiva da literatura, embora esta seja um de seus lugares privilegiados de manifestação. Sua proeminência acontece, sobretudo, na literatura romântica, a partir do final do século XVIII, e ganha novos contornos na contemporaneidade (Lamas, 2002). Essa recorrência ao mito do duplo na modernidade deve-se em muito ao fato de que, nesse contexto, a ilusão da personalidade una do Renascimento não encontra mais espaço, pois o sujeito moderno é cônscio de sua duplicidade. Como reflexo disso, estudos teórico-críticos sobre a problemática do esfacelamento do eu passam a ganhar destaque no âmbito acadêmico, buscando compreender as diferentes facetas observadas nas mais diversas representações literárias de um sujeito em crise.

$\mathrm{Na}$ literatura, o duplo manifesta-se como resultado de uma confrontação entre duas facetas de um mesmo personagem (o original e

\footnotetext{
${ }^{1}$ Doutora em letras e professora da Universidade do Estado do Rio Grande do Norte (UERN), Mossoró, RN, Brasil. Dorcid.org/0000-0002-2939-0626. E-mail: marlymouras@uol.com.br

${ }^{2}$ Doutorando em letras na Universidade do Estado do Rio Grande do Norte (UERN), Mossoró, RN, Brasil. Dorcid.org/ 0000-0003-3187-7254. E-mail: edsongleite1 @ yahoo.com.br
} 
a cópia deste), com uma continuação física e/ou psicológica entre os dois. $\mathrm{O}$ confronto realiza-se através da presença simultânea do original e da cópia, tornada possível por fenômenos como o espelhamento e a contemplação de sua imagem pelo personagem, por exemplo. $\mathrm{O}$ encontro com o duplo apresenta-se sempre como inquietante e desestabilizador para o sujeito, visto que o desdobramento introduz questionamentos sobre sua identidade e unidade. Sua materialização no texto literário efetua-se através de elementos recorrentes, como o espelho, o reflexo, a sombra, o retrato, bem como de sequências narrativas que explicitam o conflito potencialmente presente nas manifestações da duplicidade: confrontação entre o original e seu duplo, usurpação de personalidade, dúvidas sobre a verdadeira identidade e impulso para aniquilar o rival.

A partir de tais considerações, este artigo tem o objetivo de analisar como se configura a representação do tema do duplo em dois contos selecionados do escritor contemporâneo brasileiro Ignácio de Loyola Brandão. As narrativas são "A mão perdida na caixa de correio" e "As cores das bolinhas da morte", ambas publicadas no livro O homem que odiava a segunda-feira: as aventuras possíveis (2000). A análise dos contos apresentará uma visão sumária sobre a natureza da manifestação do duplo nas narrativas de Brandão, por meio de um estudo comparativo.

\section{Sobre o autor e sua obra}

Ignácio de Loyola Lopes Brandão é romancista, contista, cronista e jornalista. Publicou seu primeiro livro em 1965, uma coletânea de contos intitulada Depois do Sol; três anos depois, lançou Bebel que a cidade comeu, seu primeiro romance. Couto (2000) reconhece na literatura de Brandão uma veia de inspiração kafkiana, que metaforiza o absurdo da realidade, ao retratar em suas obras a solidão do ser humano em meio ao mundo contemporâneo (uma constante em suas obras). Essa filiação ao fantástico é explicitada pelo próprio escritor, que afirma ser essa ligação antiga e inspirada pela leitura da Bíblia: "Esse meu apego ao fantástico começou, então, com a leitura da Bíblia, dos Evangelhos - de repente o cego vê, o coxo anda. Os milagres, para mim, eram uma coisa fantástica e isso foi ficando guardado, até aparecer na minha ficção" (Brandão, 2001, p. 38). Contudo, o fantástico assume um aspecto peculiar na literatura de Brandão, pois, diferentemente de outros que 
valorizam fabulações de caráter místico, a grande maioria dos contos desse escritor enaltece o cotidiano no contexto urbano da cidade grande, tendo como personagem o indivíduo mediano, anônimo e sozinho, ainda que cercado pela multidão da metrópole. É nesse espaço de aparente normalidade que irrompe o evento insólito, estabelecendo, com isso, uma ruptura nas relações ordinárias.

Embora a fantasia seja o recurso usado pelo autor a fim de criar a atmosfera fantástica em seus contos (homens que perdem a mão ou a sombra, por exemplo), sua literatura não é, de forma alguma, alienada em relação ao contexto social circundante. Conforme afirma Silva (2001, p. 163), "a fantasia torna-se recurso para acolher melhor a realidade [...], com a diferença de que o elemento fantástico cumpre uma função de iluminar o contexto para a denúncia social, não para justificar o status quo".

Como homem de seu tempo, Brandão interessa-se pelos problemas do ser humano contemporâneo, e sua literatura aparece como forma de expressar esses conflitos. Entre os temas abordados por esse escritor em sua contística, um mostra-se particularmente interessante, tanto pela recorrência em sua obra, quanto pela especificidade como é representado na narrativa: o motivo do duplo. Uma análise preliminar permite a identificação de três variações dessa temática na produção de contos desse escritor: i) o duplo como resultado da projeção de traços da personalidade do escritor numa personagem; ii) o duplo representado pela busca e encontro da outra metade, símbolo do amor; e iii) o duplo através da cisão/mutilação do sujeito.

A concepção do duplo como projeção de traços psicológicos do autor para a construção da personagem compreende uma perspectiva de estudo antiga pela qual muitos teóricos enveredaram. Nesse caso, há uma simetria entre determinados aspectos da personalidade do autor e do ser da ficção, a ponto de este ser considerado, em certa medida, uma extensão do escritor. Contudo, deve-se ter o cuidado de não reduzir a literatura a um mero biografismo, limitando as possibilidades interpretativas do texto, o que pouco contribui com a crítica literária. Na contística de Brandão, pode-se observar essa modalidade de duplo no livro de contos Depois do sol (2005), no qual a personagem Bernardo pode ser considerada um alter ego do autor, conforme afirma Pierini (2005, p. 14-15): “Em quase todos os contos, encontra-se a figura de Bernardo, um repórter vindo do interior do Estado para tentar a sorte na capital e que, graças à sua 
profissão, pôde circular de uma camada social para a outra, conhecendo lugares, pessoas e fatos diversos e importantes".

No conto "A ascensão ao Mundo de Annuska", integrante do referido livro, uma passagem exemplifica essa relação:

Uma noite em Araraquara ainda, sentara-se à mesa e redigira febrilmente uma crítica de cinema. Levara hora e meia à máquina, catando milho, a fim de datilografá-la e deixara de ir à sessão de quinta-feira, dia em que as meninas todas lá estavam, nos lugares habituais. E correra ao jornal bissemanário do velho Rocha. Que não queria atendê-lo. Teve de invocar o nome do pai, ex-ferroviário (como o Rocha) que também escrevera vários contos (Brandão, 2005, p. 48).

Nesse trecho destacado, podem-se estabelecer três principais conexões entre os fatos narrados no conto referentes à personagem Bernardo e à vivência do escritor Brandão: a menção à cidade de Araraquara, terral natal de Ignácio; a alusão à iniciante carreira de Bernardo no jornalismo, área na qual também trabalhou o escritor; a referência ao pai de Bernardo como um escritor e ex-funcionário ferroviário, em conformidade com a trajetória de vida do pai de Brandão. Desse modo, essas evidências dão suporte à interpretação que considera Bernardo um alter ego ou simplesmente o duplo do escritor.

Uma segunda configuração assumida pelo duplo nos contos de Brandão expressa-se através do tema da constante busca empreendida pelo homem por sua metade faltante, sua alma-gêmea, numa referência ao mito platônico da androgenia. De acordo com esse mito, o amor é o meio que possibilita a reunião dos opostos, restaurando a totalidade original perdida quando da separação dos princípios masculino e feminino. Como exemplo dessa vertente, destacam-se dois contos: "Lígia, por um momento!" e " 45 encontros com a estrela Vera Fischer", ambos publicados no livro Cabeças de segunda-feira (2008). Nesses contos, a mulher amada assume a função do duplo, configurando-se como a outra metade da personagem, muito embora a tão desejada reunião das duas metades não se efetive na narrativa. No conto " 45 encontros com a estrela Vera Fischer", por exemplo, a mulher amada assume a condição de duplo, compreendida como o complemento ou a outra metade do sujeito. Um bancário, narrador e personagem do conto, descreve os supostos 45 encontros com a famosa atriz Vera Fischer. Entretanto, os encontros íntimos mencionados nunca aconteceram de fato: tudo não passava de fantasias criadas pela personagem e alimentadas pela 
indústria cultural (gastos com publicações sobre a atriz, idas ao teatro repetidas vezes para assistir à mesma peça). Esse conto apresenta, de modo exemplar, o tipo de relação intersubjetiva estabelecido pelo sujeito na era da modernidade. A atriz Vera Fischer, no conto, não passa de mera imagem representativa de um modelo de mulher socialmente valorizado, construído e mantido pela poderosa indústria cultural. Nesse caso, o encontro com a outra metade, com o complemento ausente, nada mais é do que uma ilusão: a Vera Fischer pela qual a personagem do conto se apaixonou é simplesmente um simulacro fabricado pela mídia. Como se vê, Brandão atualiza esse mito antigo da duplicidade, adequando-o ao contexto moderno.

Por fim, há a modalidade em que o fenômeno do duplo se manifesta como resultado de uma cisão/mutilação da personagem. Além da modificação efetuada no corpo, acontecem também mudanças significativas no modo como o sujeito se relaciona com as pessoas e com o mundo. A mutilação física aparece como um indício externo que tem seu correspondente interno na nova postura que o sujeito adquire perante a sociedade. É pelo processo de reflexão/esclarecimento desencadeado nas personagens que o membro cindido/mutilado assume, metonimicamente, a função do duplo, do outro que fornece a imagem especular a partir da qual o sujeito problematiza sua identidade enquanto ser social. Num processo de iluminação repentina, o sujeito consegue enxergar e compreender retrospectivamente sua postura e comportamentos adotados consigo e com os outros ao longo dos anos. Assim, a busca da "cura", realizada solitariamente pelo sujeito, representa, na verdade, uma procura pela essência do próprio eu, numa tentativa de individualizar-se num mundo cada vez mais massificado. Os dois contos, que serão analisados comparativamente na sequência deste artigo, filiam-se a essa modalidade de duplo.

\section{Confluências ficcionais: o estatuto do duplo em duas narrativas de Ignácio de Loyola Brandão}

Os dois contos de Brandão que serão analisados a seguir integram a obra O homem que odiava a segunda-feira: as aventuras possíveis, coletânea na qual os eventos insólitos, ao aparecerem sob o rótulo de "aventuras possíveis", apontam para a banalização do absurdo na sociedade atual. A escolha desses dois contos se baseou, principalmente, na correlação 
verificada nessas narrativas entre o duplo e o fantástico, já que o fenômeno da duplicidade aparece nesses textos como uma forma de manifestação do sobrenatural. Soma-se a isso a vinculação também observada nos dois contos entre a experiência da duplicação e o confronto com a morte. Essas semelhanças observadas quanto à estrutura narrativa e à temática abordada é explicada não apenas porque os textos pertencem ao mesmo autor, mas também pelo fato de os dois contos estarem reunidos em uma mesma coletânea e, em certo sentido, conectados à ideia geral expressa no título da obra, traço que supostamente atua como força aglutinadora dessas "aventuras possíveis", narradas ao longo de mais de 160 páginas. É assim que Antunes (2000, p. 257) apresenta, em linhas gerais, a coletânea de contos de Brandão: "por baixo desse mau-humor incurável, desse horror às segundas-feiras, desse horror a tudo, que vai perpassar todas as falas e reflexões dos personagens destes quatro contos e uma quase-novela, há inúmeras aventuras possíveis".

Os contos referidos são narrados em terceira pessoa, por um narrador onisciente que tem acesso livre aos pensamentos e movimentos psicológicos das personagens. As ações expressas nas duas narrativas são ambientadas no contexto da cidade grande e, graças à mobilidade dos seres ficcionais nesse espaço, é permitida ao leitor, ainda que de modo limitado e fragmentado, a visualização dos contrastes inerentes à sociedade moderna.

O protagonista de cada uma das narrativas é do sexo masculino: em "A mão perdida na caixa do correio", há um escrevente de cartório de meia idade que já visualiza a proximidade da aposentadoria; em "As cores das bolinhas da morte", por sua vez, trata-se de um juiz também de meia idade e aposentado compulsoriamente. Os dois protagonistas comungam de uma existência pacata e solitária, já que foram abandonados por suas esposas: o escrevente foi trocado pelo dono de uma locadora de vídeo, e o juiz teve sua separação provocada devido a fantasias sexuais que nutria com as juradas.

As duas narrativas têm início no exato momento em que cada uma das personagens se depara com uma situação insólita. Em "A mão perdida na caixa do correio", o escrevente vai depositar um envelope numa caixa de correio e, inesperadamente, vê sua mão cair dentro dela. $\mathrm{O}$ inusitado da amputação do membro é exatamente o modo não habitual como ela se processa: "Não sentiu dor. Nem o mais leve comichão. A mão simplesmente se desprendeu, como se estivesse presa 
por parafusos frouxos" (Brandão, 2000, p. 27). O fragmento acima transcrito dispensa qualquer comentário sobre a natureza estranha do evento. Em "As cores das bolinhas da morte", a narrativa também se inicia no exato momento em que a personagem se apercebe da perda de sua sombra: "Olhando para o chão, não viu a sua sombra. Estremeceu" (Brandão, 2000, p. 95). Nos dois contos, o acontecimento insólito inscreve-se em meio à realidade cotidiana dos sujeitos, estabelecendo uma ruptura em sua rotina. Embora os desestabilizem, os fatos são apresentados de forma bastante natural pelo narrador. Assim, diferentemente de outras narrativas, em que se cria uma atmosfera visionária na qual um fenômeno fantástico se inscreve, nesses dois contos de Brandão o insólito naturalizado parece brotar da concretude socio-histórica do contexto imediato das personagens. Esses eventos incomuns (a perda da mão e a perda da sombra) assumem importância capital nas narrativas, já que se configuram como os acontecimentos norteadores dos enredos, a partir dos quais a ação é deflagrada.

Seguindo a tendência apresentada pelo título da coletânea, os dois acontecimentos insólitos se realizam numa segunda-feira. Apesar de no conto "As cores das bolinhas da morte" os indícios da perda da sombra serem percebidos anteriormente pelo juiz, é somente numa segundafeira, quando o sol reaparece depois de períodos nublados e de céu fechado, que tal suspeita se confirma. Como funcionários públicos, a segunda-feira representa, para ambas as personagens, uma volta, após um curto período de descanso, às atividades laborais e, consequentemente, a uma rotina de vida burocratizada e normatizada.

Ao narrar o exato momento em que as personagens experimentam o sentimento da perda, os dois contos dão foco à saga empreendida pelos personagens para recuperar sua parte faltante. Nessa busca, ambos os indivíduos passam por situações incomuns parecidas, muitas delas resultado do confronto entre o racional e o irracional. A irrupção do acontecimento insólito no cotidiano mostra-se particularmente interessante pela quebra que se instaura na rotina dos seres envolvidos, visto que ambos estão ligados a ambientes burocráticos, regidos pela racionalidade e por rígidas normas de convício social: em "A mão perdida na caixa do correio", trata-se de um escrevente de cartório; em "As cores das bolinhas da morte", de um juiz aposentado. Apesar disso, os sujeitos dos dois contos apresentam-se de tal forma enredados nos sucessivos acontecimentos excepcionais que chegam a protagonizar situações que 
beiram o ridículo. O que pensar do diálogo entre o homem que perdeu a mão na caixa do correio e o atendente dos Correios? As perguntas protocolares feitas por este são completamente inadequadas para aquela situação específica: “[A mão] Tinha destinatário? Remetente? CEP correto?" (Brandão, 2000, p. 50). Essa mesma cena repete-se no conto "As cores das bolinhas da morte", quando da conversa entre o homem sem sombra, que procurava pela cientista Cristina Agostino, e o atendente da universidade, que o aconselha a consultar uma psicóloga.

Ademais, nos dois contos, a vivência da perda de uma parte do corpo considerada importante pelos sujeitos envolvidos desencadeia uma busca externa que tem como correlato interior a problematização da própria identidade do sujeito, através de questionamentos sobre a condição existencial humana na sociedade moderna. No conto "A mão perdida na caixa do correio", o momento em que a mão se desprega do braço e cai dentro da caixa do correio é bastante representativo: "O toco de braço mostrava artérias, veias, músculos e terminais de ossos limpos, secos. Pareciam microtomadas, nas quais se encaixavam os plugues da mão" (Brandão, 2000, p. 27). Nessa passagem, é possível destacar dois aspectos principais. Em primeiro lugar, a inexistência de sangue, considerado a seiva da vida, aponta, no plano físico e biológico do termo, para a falta de fluxo de vida no membro e, no plano simbólico, para o estado de vida degradante ao qual esse sujeito estava submetido. Em segundo lugar, a comparação das artérias, veias etc. com microtomadas apresenta-se particularmente interessante no contexto da contemporaneidade, dada a influência que os artefatos tecnológicos desempenham na vida diária. Aqui, a imagem da robotização do homem pode ser entendida como uma hipérbole que reflete o caráter mecânico e automático que impera nas relações sociais. Assim, concebendo a mão como representação metonímica do duplo da personagem, visualiza-se, na busca empreendida para recuperar essa parte faltante, um processo de resgate e reconhecimento da identidade do próprio sujeito.

A perda da sombra no conto "As cores das bolinhas da morte" também aponta para um estado de vida degradante do sujeito. Ao longo dessa narrativa, a personagem atesta inúmeras vezes a conexão entre o homem e a sombra, sendo esta, inclusive, considerada como condição para a existência humana. Do ponto de vista psicológico, a sombra é concebida como um estrato da psique no qual se aglomera o conjunto de conteúdos não assimilados pela personalidade, tratando-se, 
pois, de uma potencialidade latente. Admitindo-se o simbolismo da sombra, não se pode considerar, portanto, sua ausência como uma metáfora do esvaziamento do sujeito, do ceifar de sua vida? Essa interpretação se tornará mais contundente no decorrer da narrativa, quando se estreitam os laços entre o eu e o outro (a sombra). Também nesse conto de Brandão, os questionamentos existenciais afloram com maior vigor a partir da oposição que se estabelece entre essas duas faces contrárias da personalidade. Assim, problematiza-se, principalmente, a tensa e conflituosa relação entre sujeito e sociedade no processo de constituição da identidade individual.

Nos dois textos aqui analisados, observa-se, desse modo, que a parte do corpo perdida assume a configuração de duplos desses sujeitos. Além dos elementos simbólicos já destacados acima, acrescenta-se a importância que tanto a mão quanto a sombra apresentavam para tais indivíduos. A mão é símbolo por excelência de atividade, poder e dominação. Na condição de escrevente, o protagonista de "A mão perdida na caixa do correio" dependia diretamente desse membro para o desempenho de suas atividades laborais. Num plano místico, a mão continha também as "linhas de sua vida", o que permite compreender esse membro como representação metonímica da vida da personagem. Desse modo, o impacto causado em sua rotina quando da perda da mão na caixa do correio é diretamente proporcional à importância que esse membro desempenhava em sua vida: "A mão. Percebeu que tinha rodado horas, procurando se distrair com o impacto da perda. Era um estranhamento muito grande. Nem quando a mulher o tinha deixado para se juntar ao dono de uma locadora de vídeos tinha sentido tanto" (Brandão, 2000, p. 41).

De igual modo, a perda da sombra no conto "As cores das bolinhas da morte" apresenta-se como um trágico acontecimento que quebra a rotina do sujeito. Interessante perceber que esse sujeito também demonstrava certa afeição pela sombra anteriormente ao evento que acarretou a perda dela: "Ninguém se dá conta se tem sombra ou não, a maioria pouco se importa. [...] Ele não. Costumava contemplá-la ao longo do dia, cheia de variações" (Brandão, 2000, p. 96). Obviamente, a ausência da sombra intensifica o interesse antes demonstrado. Ademais, pode-se mencionar a relação íntima existente entre a personagem e sua sombra: "Gostava dessa ideia. A sombra a segui-lo. Fosse para onde fosse. Estava com medo de constatar que ela faltava" (Brandão, 2000, p. 99). Nesse contexto moderno, em que se vivencia com extrema angústia 
a solidão, a sombra parece significar muito mais do que simples reflexo projetado no chão, conforme fica demonstrado em outra passagem da narrativa: "Pois eu ia fica chatiado sem ela [a sombra], é a única amiga qui tenho" (Brandão, 2000, p. 123). Por fim, os contornos simbólicos e psicológicos atrelados à concepção de "sombra" por Jung, que a concebe como um estrato da psique do sujeito, ajudam a consumar essa relação dupla que se manifesta entre a personagem e a sombra perdida.

Nos dois contos, o fenômeno da duplicidade opera-se através de uma cisão imposta às personagens. Essa cisão instaura um processo de busca pela parte faltante, o que, num plano metafórico, aponta para a procura da verdadeira identidade do sujeito em um mundo burocratizado e governado por rígidas normas de conduta e de comportamento que inibem a liberdade individual em prol de um suposto bem-estar coletivo. Para Chevalier e Gheerbrant (2009), a mutilação assume valor simbólico de iniciação. Nas duas narrativas, essa iniciação é representada pelos questionamentos existenciais instaurados no interior dos sujeitos em razão da perda, o que os leva a uma melhor compreensão de si e do mundo a sua volta. Assim, embora o intervalo entre a cisão e o desfecho da narrativa, que resulta na morte dos dois sujeitos, seja curto, pode-se compreendê-lo como o início de uma jornada (não completada) rumo à individuação. Logo, a cisão exterior, verificada devido à perda da mão e da sombra, reflete, no plano subjetivo, um esfacelamento interior desses sujeitos, expressão da instabilidade psíquica e de uma crise de identidade.

Dessa forma, pode-se concluir que a busca da mão e da sombra nos contos "A mão perdida na caixa do correio" e "As cores das bolinhas da morte", respectivamente, remete à procura do duplo especular que permite ao sujeito diferenciar-se e reconhecer-se como uma individualidade. São pessoas cujas identidades correspondem e obedecem a demandas sociais e que, para tanto, negam e reprimem determinados conteúdos psíquicos numa tentativa de aceitação no meio social. A busca da mão e da sombra revela, simbolicamente, a procura pela verdadeira natureza e essência do ser, o resgate e o desenvolvimento das potencialidades do sujeito que o guiam no caminho de sua individuação. Nesse percurso, os elementos mão e sombra funcionam como espécie de espelho, pois, ao configurarem o outro das personagens, fornecem a imagem especular que, no nível psicológico, permite a confrontação com o duplo e a construção de uma identidade autêntica. 
Essa procura pela individualidade e pela diferenciação contrasta com os movimentos de massificação no processo de construção identitária e de dessubstancialização do sujeito humano verificadas no contexto atual, as quais acabam por igualar os sujeitos pela impossibilidade de expressão de suas potencialidades. Portanto, a perda da mão e da sombra nos contos de Brandão desperta as personagens, que pareciam viver no que Cavalcanti (1997, p. 214) define como escravidão psíquica: “A escravidão psíquica significa funcionar segundo a expectativa do outro, numa tentativa de adaptação, negando a verdadeira essência e excelência".

Nas duas narrativas, a confrontação do sujeito com a duplicidade é uma experiência que leva à morte: a busca pela parte cindida conduz irremediavelmente ao confronto com a morte. Em "A mão perdida na caixa do correio", existe, em meio a outras tantas, a situação absurda em que o protagonista é estrangulado e morto por um funcionário da repartição dos Correios. A motivação do assassinato - o medo do funcionário de perder seu emprego - revela, em última instância, a precariedade das relações humanas num mundo em que o individualismo se sobrepõe e subjuga o conceito de coletividade. Em "As cores das bolinhas da morte", o reencontro e a fusão com a sombra representam um momento repleto de significados para o juiz, já que torna possível a reintegração entre o eu e o outro. Essa fase demarca uma morte ao menos no plano simbólico, uma vez que o sujeito que emerge desse confronto diferencia-se do ser anterior cindido, que estava à procura de sua sombra.

De acordo com as categorizações do duplo apresentadas por Bargalló (1994), há, nos dois contos de Brandão analisados, o fenômeno da duplicidade como resultado de uma cisão imposta ao sujeito. É graças a isso que a mão e a sombra passam a assumir a função de duplo das personagens. Seguindo a tipologia proposta por Jourde e Tortonese (2005), verifica-se, nas duas narrativas, o duplo subjetivo, já que se trata da duplicação do próprio sujeito, e externo, uma vez que o duplo adquire uma forma física exterior representada pela mão e pela sombra.

Nota-se, pois, que a manifestação do duplo nas duas narrativas de Brandão está intimamente relacionada às infinitas possibilidades abertas pelo discurso fantástico. Em função disso, torna-se crível para o leitor a história de um ser que, inesperadamente, vê sua mão despregarse do braço e cair dentro de uma caixa de correio, e de um outro que visualiza a perda de sua própria sombra. Aqui, é a própria concepção de 
realidade que é questionada, uma vez que o acontecimento incomum irrompe dessa mesma realidade. Desse modo, o fantástico não é estranho à vida diária dos sujeitos, mas brota dela, desestabilizando-a.

Além de permitir o fenômeno da duplicação, o fantástico abre também espaço, nas narrativas de Brandão, para a crítica a determinados aspectos da sociedade atual. Entre esses, um merece atenção especial pela recorrência com que aparece nas duas narrativas e pela importância que desempenha na construção da trama: o conceito de racionalidade, aqui incluído o campo das ciências em geral. Ambos os acontecimentos fantásticos, pontos de partida das duas narrativas, opõem-se claramente à razão, afinal, a perda da sombra e da mão nas circunstâncias em que se processaram não se encaixam no conjunto de ações aceitáveis e consideradas possíveis pelo corpo social. Exteriores ao sistema de pensamento que governa a sociedade atual, tais eventos estabelecem uma quebra e são, portanto, uma ameaça para sua manutenção. A esse respeito, veja-se o que pensam Adorno e Horkheimer (2006, p. 72):

O sistema deve ser conservado em harmonia com a natureza. Do mesmo modo que os fatos são previstos a partir do sistema, assim também os fatos devem por sua vez confirmá-lo. [...] $\mathrm{O}$ pensamento que não consegue harmonizar o sistema e a intuição desrespeita algo mais do que simples impressões visuais isoladas: ele entra em conflito com a prática real. Não apenas a ocorrência esperada deixa de ter lugar, mas também o inesperado acontece: a ponte cai, a simetria definha, o remédio faz adoecer.

Os referidos autores veem o pensamento racional como um sistema uno e coerente a partir do qual derivam as particularidades. Estas, por sua vez, são explicadas e confirmadas pelo sistema, criando-se, portanto, um círculo vicioso em que o equilíbrio aparece como resultado da harmonia entre o sistema e a natureza. Nos dois contos de Brandão aqui analisados, essa harmonia é quebrada, culminando no desequilíbrio e no questionamento do próprio sistema. Ademais, é a partir dessa ruptura que a trama narrativa ganha corpo, tornando-se o centro irradiador de grande parte das questões e dos conflitos vivenciados pelas personagens. Ante a experiência do acontecimento insólito, os sujeitos, nos dois contos, buscam reestabelecer a ligação entre o sistema e os fatos particulares vivenciados (a perda da mão e da sombra), ao procurarem por uma explicação racional baseada na ciência. A postura assumida por esses sujeitos apresenta-se, inclusive, 
extremamente arraigada no âmago da sociedade moderna, já que o homem se encontra subordinado à razão e faz dela um verdadeiro mito. Uma vez que o sistema não consegue dar conta desses acontecimentos insólitos particulares (as personagens não encontram explicação científica plausível que as ajude a enfrentar a situação), ambas abandonam a linha de pensamento racional, deixando-se tragar pela atmosfera misteriosa que as rodeia. Portanto, a crítica feita à razão e à ciência nessas narrativas parte precisamente da insuficiência desses domínios do conhecimento para explicar um fato concreto, a saber, a perda da mão e da sombra.

Disso depreende-se uma característica que marca a espécie humana ao longo dos tempos: o homem está sempre buscando explicar os acontecimentos que o cercam. O homem moderno esclarecido subjugou outras formas de explicação do universo. Nessa sociedade desmitologizada, o homem erige a racionalidade como forma suprema de conhecimento, em detrimento da mitologia presente nas culturas primitivas. Entretanto, o que Adorno e Horkheimer (2006) defendem é que entre o mito e a razão verifica-se não uma diferença qualitativa, mas apenas maneiras diferentes de relacionamento entre o homem e a natureza. A razão é, por conseguinte, o mito moderno no qual o homem se engendrou. A tentativa de fugir da mitologia e de outras formas de conhecimento consideradas menores é também um retorno ao mito. Dessa forma, as narrativas de Brandão problematizam essa autossuficiência da razão e da ciência, apontando seus impasses e suas limitações, já que nem tudo pode ser explicado por tais instâncias.

A crítica à insuficiência do conhecimento científico para explicar os problemas enfrentados pelo homem moderno é endossada pela presença, nas duas narrativas, de imagens de bibliotecas que fogem ao padrão convencional. Como se sabe, a biblioteca constitui um repositório do conhecimento produzido e acumulado pela humanidade através dos séculos e reflete a tentativa do homem de entender a si mesmo e ao mundo em sua volta. Em "A mão perdida na caixa do correio", a biblioteca é formada por títulos que apontam para eventos incomuns (Enciclopédia do inexplicável, de Jerome Clark; O estranho e o extraordinário, de Charles Berlitz; e Casos malditos, de Charles Fort). Entretanto, nem mesmo esses livros, inseridos no campo epistemológico do inusitado e do irreal, trazem relatos que ajudem o homem a resolver o problema da perda da mão. Em "As cores das bolinhas da morte", a 
biblioteca é formada por um espaço totalmente vazio, à exceção de um livro volumoso. Entretanto, tal livro, que sintetizaria o pensamento universal, contém apenas páginas em branco. Se a síntese de todo o pensamento universal está presente nessa obra, conclui-se, portanto, pela sua nulidade, expressa pela imagem do livro em branco. Nos dois casos, consideradas as devidas especificidades, o que está em pauta é a insuficiência do conhecimento lógico e científico para explicar a realidade das personagens. Assim como a biblioteca do conto "A biblioteca de Babel", de Jorge Luis Borges (1999), aparece como metáfora do universo, as bibliotecas apresentadas por Brandão nessas duas narrativas também imprimem um saber significativo sobre o homem e a sociedade moderna: de um lado, existe a ilogicidade e a irracionalidade que imperam no cotidiano, expressas pelos títulos de livros de teor insólito presentes em "A mão perdida na caixa do correio"; de outro, apresenta-se o esvaziamento dos sujeitos, a inexistência de valores e de verdades, sinalizados pelas páginas em branco do livro em "As cores das bolinhas da morte". Nesse último caso, o não registro de uma tradição, bem como de sua história e sua memória, são emblemáticos, de modo direto ou indireto, do esvaziamento da identidade social do ser.

Pode-se destacar também o tom risível que adquirem algumas situações vivenciadas pelos seres nos dois contos. Abundantes nos dois textos, elas conectam-se, direta ou indiretamente, ao fenômeno insólito motivador da trama (a perda da mão e da sombra), brotando com naturalidade ao longo de toda a história. Segundo Chevalier e Gheerbrant (2009), a mutilação está, quase sempre, relacionada a uma desqualificação, posto que imprime uma marca que diferencia negativamente o sujeito das demais pessoas que constituem a sociedade: "O deformado, o amputado, o estropiado têm isso em comum: acham-se colocados à margem da sociedade humana" (Chevalier e Gheerbrant, 2009, p. 628). Assim, a deformidade física das personagens, na medida em que as diferencia das demais pessoas, aparece, a princípio, como um campo em potencial do riso a ser explorado. Tratando especificamente do riso, Bergson (1983) destaca alguns aspectos importantes sobre ele: i) é próprio do ser humano; ii) é insensível; iii) funciona como uma forma de correção de uma imperfeição individual ou coletiva; e iv) é inconsciente, pois o sujeito cômico torna-se visível para os outros e invisível para si mesmo. Nos 
contos analisados, verificam-se com nitidez esses aspectos acima apontados: as personagens são seres inseridos num corpo social e, devido a uma imperfeição causada pela perda de uma parte de seu corpo, diferenciam-se negativamente dos demais. À medida que se entregam por completo à tentativa de recuperar a parte do corpo mutilada, vivenciam situações inusitadas que os ridicularizam e, assim, provocam o riso no expectador (e no leitor). Esse efeito é conseguido graças à insensibilidade do narrador (e mais uma vez do leitor que o acompanha) em relação aos acontecimentos, pois no riso não há espaço para a emoção. Bergson (1983) lembra ainda que a ridicularização é um fator propiciador do riso. Em Brandão, o esfacelamento do corpo ou a inexistência da sombra constituem atributos que causam a diferença. Assim, a quebra de um protótipo pode motivar o riso. Nos dois contos, essas situações aparecem em abundância. Como não rir ao ler o diálogo absurdo entre o homem que perdeu a mão e o atendente dos Correios? O mesmo efeito se observa quando o homem sem sombra procura informações em uma universidade sobre uma cientista que supostamente estudava o desaparecimento de sombras.

Em alguns casos, o humor é indissociável de uma crítica a determinados aspectos da sociedade brasileira. No conto "A mão perdida na caixa do correio", enquanto a personagem vivencia a angústia da perda do membro, um transeunte dispara: "'Onde comprou essa? Legal, tio! Boa pra pedir esmola'” (Brandão, 2000, p. 46). Em outra passagem, a própria personagem ridiculariza e zomba da situação em que se encontra: "Um escrevente sem mãos? O último sonho que resta a quem perde a mão é tornar-se pirata" (Brandão, 2000, p. 47). Na narrativa "As cores das bolinhas da morte", verifica-se o mesmo tom de humor impresso à narrativa: "Claro, já surgiu o mercado negro. Gente que falsifica sombras. Trapaceiros desviam a sombra dos outros. Embustes de todo tipo. Para tudo há um logro'" (Brandão, 2000, p. 107). Assim, embora circulando ao longo dos anos no domínio extraoficial e na literatura considerada menor (Bakhtin, 1987), o riso aparece nos contos de Brandão como importante ferramenta que ajuda a compor uma visão crítica do homem e da sociedade modernos. Bakhtin (1987, p. 81) afirma que "o riso, menos do que qualquer outra coisa, jamais poderia ser um instrumento de opressão e embrutecimento do povo. [...] Ele permaneceu sempre uma arma de liberação nas mãos do povo". Nos contos de Brandão aqui 
analisados, o riso aparece atrelado a uma crítica social contundente, atuando como importante ferramenta de denúncia de condições sociais degradantes às quais o homem moderno está submetido. Desse modo, o "sério" é expresso por meio de uma literatura bemhumorada, dialética intrínseca à produção de contos desse escritor.

Por fim, ambos os contos podem ser inseridos dentro de uma tradição cuja fundação se dá através de textos literários consagrados. Por um lado, pode-se apontar um possível diálogo entre "A mão perdida na caixa de correio" e o conto "O nariz", do russo Nicolau Gogol. Nesse conto, que também se filia ao fantástico, o major Kovalev, assessor do colégio, percebe, ao acordar, que seu nariz sumira inexplicavelmente:

Kovalev, assessor do colégio, levantou-se cedo, murmurando "Brr", o que fazia sempre ao acordar, embora não apresentasse qualquer explicação para tal procedimento. Kovalev espreguiçou-se e mandou que lhe trouxessem um espelho de tamanho médio, dos que se colocam em cima da mesa. Tudo isso na intenção de observar uma borbulha que na véspera lhe tinha nascido no nariz. Mas, para seu grande espanto, viu que, no sítio do nariz, tinha apenas uma superfície lisa. Kovalev, alarmado, pediu água e esfregou os olhos com um pano molhado: era verdade, tinha-lhe desaparecido o nariz. Apalpou-se; beliscou-se, para se convencer de que não estava a dormir. Não, pareceu-lhe que estava acordado. O assessor Kovalev saltou então da cama e lavou-se: nem sinais do nariz... Vestiu-se prontamente e voou para o posto da polícia (Gogol, 1983, p. 169).

Assim como no conto de Brandão, em que o protagonista se vê, inesperadamente, sem sua mão, a personagem do conto de Gogol também percebe, ao acordar e ver sua imagem refletida no espelho, que uma parte de seu corpo também desaparecera: o nariz. Na busca empreendida para recuperar o membro perdido, ambos os seres enfrentam situações absurdas. Tal como na narrativa de Brandão, no conto do escritor russo, o membro cindido, no caso o nariz, assume a função de duplo. Apesar disso, o conto de Gogol apresenta algumas especificidades: o nariz, em determinada parte do conto, apresenta-se como uma personagem com vida própria, dotada, portando, de ação; e, no final do conto, Kovalev consegue recuperar o nariz que, da mesma forma inexplicável como despregara da superfície do rosto, retorna a seu lugar de origem. Vê-se, portanto, um final bastante diferente do conto de Brandão, em que, além de o protagonista não conseguir 
recuperar sua mão perdida na caixa do correio, perde ainda a vida em consequência da busca empreendida por esse membro.

Já a narrativa "As cores das bolinhas da morte" filia-se a uma tradição literária antiga que tematiza o motivo literário da perda da sombra pelos personagens. Desse modo, tal narrativa pode ser inserida no conjunto de uma tradição que estabelece diálogos com outras narrativas produzidas em diferentes épocas. Entre essas narrativas, pode-se citar a narrativa de Chamisso "A maravilhosa história de Pedro Schlemihl", que, segundo Moraes (2002, p. 101), precipita "a criação de várias [narrativas] com enredos semelhantes". É o caso de "Aventuras da noite de São Silvestre", de Hoffmann (1983), e "A sombra", de Andersen (1983). No primeiro, Erasmo Spikher dá seu reflexo para Giulietta. A perda do reflexo cai sobre ele como uma maldição, sendo relegado pela sociedade e pela própria família. No segundo, um ser conhecido como "o sábio" depara-se com uma situação inusitada: certo dia, sua sombra desprende-se de seu corpo e desaparece. Depois de um tempo, ela retorna, assumindo um corpo próprio. A sombra, agora corporificada, convence o sábio a tornar-se sua sombra. Nessa inversão de valores, a sombra casa-se com uma princesa e mata o sábio, que assumira a condição de sombra da personagem sombra.

A recorrência de narrativas que tematizam a perda da sombra ressalta, pois, a importância da inscrição desse motivo literário em diferentes épocas, permitindo ao leitor analisar a narrativa como pertencente a uma tradição. Praticamente todas essas narrativas inserem, inevitavelmente, $\mathrm{o}$ questionamento sobre a identidade no interior do sujeito. A cisão operada por meio da separação entre o corpo e a sombra é sempre sentida como a perda de uma parte importante e integrante do sujeito, resultando numa diferenciação negativa em relação aos demais membros do corpo social e, consequentemente, no enfraquecimento do sujeito. Entretanto, enquanto nas demais narrativas a perda da sombra parece estar atrelada a uma atitude consciente da personagem, no conto de Brandão, tal evento insurge repentinamente, surpreendendo inclusive $\mathrm{o}$ leitor. $\mathrm{O}$ acontecimento insólito desestabiliza o protagonista da história, provocando uma reviravolta em seu cotidiano. Diferentemente das demais narrativas, nas quais a perda da sombra é percebida por todos, levando o sujeito portador dessa particularidade à completa exclusão das relações sociais, a personagem desse conto de Brandão passa praticamente despercebida em meio à massa de desconhecidos habitantes 
das cidades grandes, ressaltando, com isso, a solidão vivenciada pelo homem moderno: "Ficou parado, as pessoas passavam indiferentes, ninguém repara em nada" (Brandão, 2000, p. 99).

\section{Considerações finais}

Nos contos de Brandão, o tema da dualidade aparece como consequência ou desdobramento de uma situação insólita vivenciada pelas personagens, situação essa que assume formas variadas: primeiro, um evento inusitado acomete-as, quando acontece a perda de uma parte de seu corpo; segundo, uma busca é instaurada na tentativa de recuperação da parte mutilada, a qual passa a configurar o duplo da personagem; por fim, o duplo é resultado de uma cisão que é valorada pelas possibilidades abertas pelo discurso fantástico. Na narrativa "A mão perdida na caixa do correio", a mão que inesperadamente cai dentro da caixa funciona, metonimicamente, como duplo do protagonista; em "As cores das bolinhas da morte", o duplo configurase no papel assumido pela sombra perdida.

Desse modo, o processo de construção da identidade do sujeito, problematizada no contexto da sociedade moderna, apresenta-se como tema privilegiado na ficção de Brandão. A maioria de seus textos aborda a penosa luta do homem não só pela sobrevivência física, mas também, e principalmente, pela estabilidade psíquica num cenário inóspito para a constituição egoica. Nesse contexto, visualiza-se a angústia do sujeito moderno, largado à própria sorte. O leitor acompanha, página a página, $\mathrm{o}$ drama de personagens irremediavelmente presas à engrenagem do capitalismo, a uma rotina automatizada e burocratizada, que poda as possibilidades humanas de realização pessoal e o desenvolvimento da individualidade. Assim, as narrativas de Brandão analisadas, ao mesmo tempo que criticam tais comportamentos e atitudes, demonstram também o dificultoso caminho rumo à constituição de uma subjetividade autêntica numa sociedade burocratizada e normatizada.

\section{Referências}

ADORNO, Theodor Wiesengrund; HORKHEIMER, Max (2006). Dialética do esclarecimento: fragmentos filosóficos. Rio de Janeiro: Zahar. 
ANDERSEN, Hans Christian (1983). A sombra. In: VON CHAMISSO, Adalberto et al. Contos dos homens sem sombra. Lisboa: Estampa. p. 203-215.

ANTUNES, José Pedro (2000). Apesar das segundas-feiras: sobre o homem que odiava a segunda-feira. Revista Letras, n. 54, p. 257-259, jul./dez.

BAKHTIN, Mikhail (1987). Rabelais e a história do riso. In: BAKHTIN, Mikhail. A cultura popular na Idade Média e no Renascimento: o contexto de François Rabelais. São Paulo: Hucitec. p. 51-123.

BARGALLÓ, Juan (1994). Hacia una tipología del doble: el doble por fusión, por fisión y por metamorfosis. In: BARGALLÓ, Juan. (Ed). Identidad y alteridade: aproximación al tema del doble. Sevilla: Alfar. p.11-26.

BERGSON, Henri (1983). O riso: ensaio sobre a significação do cômico. 2. ed. Rio de Janeiro: Zahar.

BORGES, Jorge Luis (1999). A biblioteca de Babel. In: BORGES, Jorge Luis. Ficções. Obras completas. São Paulo: Globo. v. 1.

BRANDÃO, Ignácio de Loyola (2000). O homem que odiava a segunda-feira: as aventuras possíveis. 3. ed. São Paulo: Global.

BRANDÃO, Ignácio de Loyola (2001). Entrevista. Cadernos de literatura brasileira: Ignácio de Loyola Brandão, Rio de Janeiro, n. 11, p. 35-57.

BRANDÃO, Ignácio de Loyola (2005). Depois do sol. 2. ed. São Paulo: Global.

BRANDÃO, Ignácio de Loyola (2008). Cabeças de segunda-feira. 5. ed. São Paulo: Global.

CAVALCANTI, Raissa (1997). O mito de Narciso: o herói da consciência. 10. ed. São Paulo: Cultrix.

CHEVALIER, Jean; GHEERBRANT, Alain (2009). Dicionário de símbolos: mitos, sonhos, costumes, gestos, formas, figuras, cores, números. 24. ed. Rio de Janeiro: José Olympio.

COUTO, Rita (2000). Kafka nos trópicos. EccoS Revista Científica, São Paulo, v. 2, n. 1, p. 105-107, jan./jun.

GOGOL, Nicolau (1983). O nariz. In: VON CHAMISSO, Adalberto et al. Contos dos homens sem sombra. Lisboa: Estampa. p. 163-200.

HALL, Stuart (2006). Identidade cultural na pós-modernidade. 11. ed. Rio de Janeiro: DP\&A.

HOFMANN, Ernst Theodor Amadeus (1983). As aventuras da noite de S. Silvestre. In: VON CHAMISSO, Adalberto et al. Contos dos homens sem sombra. Lisboa: Estampa. p. 119-160. 
JOURDE, Pierre; TORTONESE, Paolo (2005). Visages du double: un theme littéraire. Paris: Armand Colin.

LAMAS, Berenice Sica (2002). Lygia Fagundes Telles: imaginário e a escritura do duplo. Tese (Doutorado em Letras) - Universidade Federal do Rio Grande do Sul, Porto Alegre.

MORAES, Eliane Robert (2002). A vida dos simulacros. In: MORAES, Eliane Robert. O corpo impossível. São Paulo: Iluminuras. p. 93-106.

PIERINI, Fábio Lucas (2005). Fantástico e alegoria em $\mathrm{O}$ homem que odiava a segunda-feira, de Ignácio de Loyola Brandão. Dissertação (Mestrado em Estudos Literários) -Universidade Estadual Paulista “Júlio de Mesquita Filho”, Araraquara.

SILVA, Deonísio da (2001). As mãos sujas: o longo fôlego das histórias curtas de um historiador solidário. Cadernos de literatura brasileira: Ignácio de Loyola Brandão, Rio de Janeiro, n. 11, p. 161-169.

Recebido em 30 de maio de 2017.

Aprovado em 7 de janeiro de 2018.

\section{resumo/abstract/resumen}

\section{Sob o domínio do duplo: um estudo comparativo de dois contos de Ignácio de Loyola Brandão}

Antonia Marly Moura da Silva

Francisco Edson Gonçalves Leite

Da tradição à modernidade, figurações do duplo denotam o prestígio da fantasia e do imaginário no vasto espaço da literatura. Na contemporaneidade, os dramas humanos são elementos inspiradores na composição do esfacelamento do eu, tornando-se uma das vias pelas quais a crise da subjetividade é representada na literatura. Assim, o presente artigo analisa as configurações assumidas pelo duplo nos contos "A mão perdida na caixa de correio" e "As cores das bolinhas da morte", integrantes da obra O homem que odiava a segunda-feira: as aventuras possíveis, de Ignácio de Loyola Brandão (2000). Nas duas narrativas, a perda de uma parte física dos personagens centrais é o traço instigador de uma realidade fantástica. As partes mutiladas assumem, simbólica e metonimicamente, a condição de duplo das personagens e, a partir disso, uma saga é empreendida na tentativa de reincorporação dessa parte faltante ao corpo. O sentimento de incompletude gerado pela mutilação impacta profundamente na psicologia dessas personagens, arrancando-as de uma rotina 
de vida burocratizada e rigidamente normatizada para lançá-las num mundo de surpresas e num cotidiano imprevisível.

Palavras-chave: duplo, fantástico, Ignácio de Loyola Brandão.

\title{
Under the domain of double: a comparative study of two short stories by Ignácio de Loyola Brandão
}

\author{
Antonia Marly Moura da Silva \\ Francisco Edson Gonçalves Leite
}

Throughout literary tradition, the figure the double denotes the importance of fantasy and of the imaginary in the vast space of literature. In the contemporary period, human dramas inspire works that broach the shattering of the self, and become one of the ways in which literature represents the crisis of subjectivity. The present article analyzes the configurations assumed by the double in the short stories "A mão perdida na caixa do correio" and "As cores das bolinhas da morte", that appear in the volume O homem que odiava a segunda-feira: as aventuras possiveis by Ignácio de Loyola Brandão (2000). In both narratives, the loss of a physical part of the central characters is the main feature of a fantastic reality. The mutilated parts assume, symbolically and metonymically, the status of the characters' double. The mutilation serves the starting point of an adventure to reincorporate the missing body part. The sense of incompleteness generated by the mutilation has a profound impact on the characters' psychology, removing them from a routine of bureaucratized and rigidly standardized life and throwing them into a world of surprises and into an unpredictable daily life.

Keywords: double, fantastic, Ignacio de Loyola Brandão.

\section{Bajo el dominio del doble: un estudio comparativo de dos cuentos de Ignacio de Loyola Brandão}

Antonia Marly Moura da Silva

Francisco Edson Gonçalves Leite

De la tradición a la modernidad, figuraciones del doble denotan el prestigio de la fantasía y de lo imaginario en el vasto espacio de la literatura. En la contemporaneidad, los dramas humanos son elementos inspiradores en la composición de la desintegración del yo, convirtiéndose en una de las vías por las cuales la crisis de la subjetividad se representa en la literatura. Así, el presente artículo analiza las configuraciones asumidas por el doble en los cuentos A mão perdida na caixa de correio y As cores das bolinhas da morte, integrantes de la obra $O$ homem que odiava a segunda-feira: as aventuras possíveis de Ignacio de Loyola Brandão (2000). En las dos narrativas, la pérdida de una parte física de los personajes centrales es el rasgo instigador de una realidad 
fantástica. Las partes mutiladas asumen, simbólica y metonímicamente, la condición de doble de los personajes y, a partir de eso, una saga es emprendida en la tentativa de reincorporación de esa parte faltante al cuerpo. El sentimiento de incompletud generado por la mutilación impacta profundamente en la psicología de esos personajes, arrancándolos de una rutina de vida burocratizada y rígidamente normalizada para lanzarlos en un mundo de sorpresas y en un cotidiano imprevisible.

Palabras clave: doble, fantástico, Ignacio de Loyola Brandão. 